\title{
PENANAMAN NILAI-NILAI AGAMA ISLAM MELALUI KEGIATAN EKSTRAKURIKULER PRAMUKA DI SMP PGRI JOGOROTO - JOMBANG
}

\author{
Solechan \\ solehchan89@gmail.com \\ STIT al-Urwatul Wutsqo - Jombang \\ Etik Fatmawati \\ etikfatmawati918@gmail.com \\ STIT Al-Urwatul Wutsqo Jombang
}

\begin{abstract}
Scout education in Indonesia is an important aspect of national education and is part of the history of Indonesia's struggle. In its development, scouting education has begun to be less attractive and is considered a monotonous activity and what is learned is only that. Whereas behind the simplicity of scouting education, scouting activities can be observed seriously and will develop all the potential that has been bestowed by Allah to humans related to Islamic religious values contained in the basic principles of scouting. The purpose of this research is to describe the cultivation of Islamic religious values through scout extracurricular activities at SMP PGRI Jogoroto. Supporting and inhibiting factors for planting Islamic religious values through scout extracurricular activities at SMP PGRI Jogoroto. This type of research includes field research using a qualitative approach. Data collection techniques through interviews, observation, and documentation. Data analysis using data reduction, data display and verification. Furthermore, the data validity test technique is through participation extension, observation persistence, and triangulation. The result of this research is the method of planting Islamic religious values, namely the method of advising, the method of letting go, and the method of modeling. The material for planting Islamic religious values is the values of faith and moral values. Supporting factors: psychological factors in the form of student motivation, social environmental factors, learning approach factors. Inhibiting factors, namely the lack of parental education for children, a less supportive environment, and differences in student IQ.
\end{abstract}

Keywords: Cultivation, Islamic Values, Scouting

Urwatul Wutqo, Jurnal Kependidikan dan Keislaman. https://jurnal.stituwjombang.ac.id/index.php/UrwatulWutsqo 


\section{Pendahuluan}

Persoalan yang dialami bangsa ini sebenarnya adalah menyangkut akhlak, moral, atau etika. ${ }^{1}$ Hal yang memungkinkan untuk meminimalisir dekadensi moral anak bangsa adalah dengan diprioritaskan sebuah pendidikan. Kenyataan di lapangan bahwa debat akademik dibidang pendidikan tidak pernah selesai dan itu tidak akan selesai. ${ }^{2}$

Pendidikan diartikan sebagai latihan mental, moral dan fisik yang bisa menghasilkan manusia berbudaya tinggi sehingga bisa menumbuhkan personalitas (kepribadian) serta menanamkan rasa tanggung jawab. Manusia memiliki kepribadian yang unik yang membedakannya dengan kepribadian manusia lainnya. Namun di dalam diri mausia terdapat beberapa potensi dasar (fitrah) yang sama sebagai makhluk individu. ${ }^{3}$

Adanya dinamika kurikulum di Indonesia yang selalu berubah. Telah membuat kebanyakan lembaga sekolah mengalami kebingungan. Setiap ganti menteri pendidikan maka akan ganti pula kurikulumnya. ${ }^{4}$ Diantara perubahan kurikulum yang ada di kurikulum 2013 adalah adanya sistem evaluasi aspek kognitif, afektif dan psikomotorik yang berbasis pada sistem tes dan portofolio. Sehingga pembelajaran bisa berjalan secara holistik dan menyenangkan. ${ }^{5}$

Gerakan pramuka merupakan gerakan (lembaga) pendidikan nonformal yang komplementer dan suplementer (melengkapi dan memenuhi) pendidikan yang diperoleh anak/remaja/pemuda dirumah dan di sekolah, pada segmen yang belum ditangani oleh lembaga pendidikan kepramukaan dan metode pendidikan kepramukaan di alam terbuka (Outdoor Activity) yang sekaligus dapat menjadi upaya "self education" bagi dan oleh anak/remaja/pemuda/pramuka sendiri. ${ }^{6}$

Cinta alam dan kasih sayang sesama manusia, dalam Islam perlu ditumbuhkan agar terjaga sebuah persatuan ukhuwah insaniyah. Manusia sebagai khalifah di bumi memegang peranan penting dalam menjaga dan memelihara segala ciptaan Allah dengan penuh kasih sayang, sebab manusia juga dikaruniai sebuah akal. Nilai patuh, bermusyawarah, rela menolong, tabah, rajin, terampil, disiplin, berani, dan setia tercermin juga pada ajaran Islam sebagai alat terjalinnya sebuah hubungan yang baik. Hubungan baik itu terjalin dengan Allah (Hablum

\footnotetext{
${ }^{1}$ Imam Suprayogo, Pengembangan Pendidikan Karakter, (UIN Maliki Press, 2013), 3.

2 Ahmad Tafsir, Epistimologi untuk Ilmu Pendidikan Islam, (Bandung: 1995), 46.

${ }^{3}$ H. Ramayulis, Ilmu Pendidikan islam (Jakarta: Kalam Mulia, 2002), 15.

4 Salahudin, Anas dan Irwanto Alkrienciehie, Pendidikan Karakter: Pendidikan Berbasis Agama dan Budaya Bangsa, (Bandung:Pustaka Setia, 2013),159.

5 Salahudin, Anas dan Irwanto Alkrienciehie, Pendidikan Karakter: Pendidikan Berbasis Agama dan Budaya Bangsa, (Bandung:Pustaka Setia, 2013),172.

6 Kwartir Nasional-Gerakan Parmuka, Kursus Pembina Pramuka Mahir Tingkat Dasar (Jakarta:t.p.2011), 26.
} 
MinaAllah), maupun hubungan dengan manusia (Hablum Minannaas), karena pada dasarnya manusia juga tidak dapat hidup sendiri tanpa bantuan makhluk lain (Muamalah).

Berdasarkan keadaan yang demikian maka mendorong peneliti untuk mengadakan penelitian di salah satu lembaga pendidikan yang menyelenggarakan kegiatan ekstrakurikuler pramuka, lembaga tersebut adalah SMP PGRI Jogoroto. Pendidikan pramuka yang diselenggarakan di SMP PGRI Jogoroto dijadikan ekstrakurikuler wajib. Selain itu, kegiatan ekstrakurikuler pramuka di SMP PGRI Jogoroto menanamkan nilai-nilai agama Islam yang disesuaikan dengan materi kepanduan. Adapun materi kepanduan juga memilki perbedaan dengan sekolah lain yaitu sebelum mulai kegiatan pramuka diawali dengan membaca do'a, ketika kegiatan pramuka berlangsung terdengar suara adzan maka berhenti sejenak untuk mendengarkan adzan beserta menjawabnya. ${ }^{7}$

\section{Tinjauan tentang Ekstrakurikuler Pramuka}

Kegiatan ekstrakurikuler pramuka adalah kegiatan yang dilakukan di luar jam pelajaran tatap muka, dilaksanakan di sekolah atau di luar sekolah agar lebih memperkaya dan memperluas wawasan. Pengetahuan, dan kemampuan yang telah dipelajari dalam berbagai mata pelajaran dalam kurikulum. ${ }^{8}$

Tujuan ekstrakurikuler pramuka yaitu bisa membentuk dan menambah wawasan peserta didik dari segi pengetahuan, sikap dan praktek, bisa menumbuhkan kompetensi siswa seperti minat dan bakat dalam rangka membina menjadi pribadi yang unggul, bisa menambah pengetahuan dan bisa mengelompokkan dan membedakan setiap mata pelajaran. Selain itu tujuan pramuka menurut Kwatir Nasional Gerakan pramuka adalah pertama, membentuk manusia yang berkarakter, mempunya pribadi dan akhlak yang baik, memiliki kecerdasan yang tinggi dan sehat jasmani serta rohani. Kedua, Menjadi warga Negara yang meliliki jiwa pancasila, serta tunduk kepada NKRI, mempunyai sikap peduli pada sesama. ${ }^{9}$

Asas Pelaksanaan Ekstrakurikuler yaitu bisa menjadi wadah untuk menyalurkan bakat, bisa menjadi cara untuk meningkatkan pengetahuan peserta didik dari segi kognitif, sikap dan praktek, harus ada planning, persiapan, pendanaan yang telah dikaji dan hitung dengan baik sebelum melakukan program ekstrakulikuler pramuka, perlu adanya sistem evaluasi yang tepat, sehingga tujuan pramuka bisa tercapai.

\footnotetext{
7 Ali Mashar, Pembina Pramuka, SMP PGRI Jogoroto Jombang, 10 April 2017.

8 Suryosuboto, Proses Belajar Mengajar di Sekolah, (Jakarta: Rineka Cipta, 1997), 271.

9 Gerakan Pramuka Anggaran Dasar dan Anggaran Rumah Tangga, (Kwartir Nasional Gerakan Pramuka, 2009), 26.
} 


\section{Hasil Penelitian dan Pembahasan}

\section{A. Penanaman Nilai-nilai Agama Islam melalui Kegiatan Ektrakurikuler Pramuka di SMP PGRI Jogoroto.}

\section{Penanaman Nilai-nilai Agama Islam}

Kegiatan ekstrakurikuler pramuka di SMP PGRI Jogoroto merupakan kegiatan ekstrakurikuler wajib yang merupakan hasil perubahan dari sistem kurikulum 2013. Dimana Orientasi pengembangan kurikulum 2013 yaitu tercapainya kompetensi yang berimbang antara sikap, keterampilan dan pengetahuan, selain itu juga cara pembelajaran yang holistik dan menyenangkan. Melalui kegiatan ekstrakurikuler ini setidaknya bisa dijadikan sebagai upaya penanaman nilai-nilai agama Islam sehingga anak mampu mengamalkan pengetahuannya dengan baik dan benar dalam kehidupan sehari-hari dengan kesadaran tanpa paksaan.

Hal ini sesuai dengan pernyataan oleh Zakiyah, nilai adalah Sebuah konsep tentang baik buruk, haq dan bathil serta benar atau salah. Dengan nilai tersebut akan memperngaruhi manusia dalam mindset, perilaku, sikap, dan perasaan manusia dalam kehidupan sehari-hari. Sehingga diperlukan sebuah proses agar nilai ini bisa menjadi bagian dari diri individu. Melalui proses tersebut akan terjadi proses sosialisasi nilai dan internalisasi nilai. ${ }^{10}$

Jika nilai diterapkan dalam proses belajar mengajar dapat diartikan sebagai pendidikan yang nilai dijadikan tolak ukur dari keberhasilan yang akan dicapai dalam hal ini disebut dengan pendidikan nilai. Pendidikan nilai adalah penanaman dan pengembangan nilai-nilai dalam diri seseorang. Nilai ini akan diinternalisasikan, dipelihara dalam proses belajar mengajar serta menjadi pegangan hidupnya. ${ }^{11}$

Adapun pedoman yang dipakai oleh seorang pembina dalam penanaman nilai-nilai agama Islam melalui kegiatan ekstrakurikuler pramuka di SMP PGRI Jogoroto terdiri dari berbagai aspek nilai, yaitu:

\section{a. Nilai Kebenaran}

Implementasi pramuka sebagai bentuk penanaman kepada peserta didik harus sesuai dengan SKU golongan penggalang dimana semua anggota pramuka wajib menepati Tri Satya dan mengamalkan Dasa Darma pramuka. Nilai kebenaran dalam pedoman penanaman nilai-

10 Moch. Sya'roni Hasan. "Internalisasi Nilai Toleransi Beragama”. DAR EL-ILMI : Jurnal Studi Keagamaan, Pendidikan Dan Humaniora 6 (1), 2019, 79-111. http://www.ejurnal.unisda.ac.id/index.php/dar/article/view/1469.

11 Zakiyah, Qiqi Yuliati dan Rusdiana, Pendidikan Nilai; Kajian Teori dan Praktek di Sekolah, (Bandung: Pustaka Setia, 2014), 147. 
nilai agama Islam adalah berdasarkan Al Qur'an dan hadis. Jadi, upaya penamanan di pramuka tidak lepas juga dari penilaian oleh guru PAI, contoh: kegiatan pramuka di adakan mengaji maka yang menguji adalah guru PAI.

b. Nilai Kebaikan

Apapun prosesnya yang dikehendaki adalah kebaikan kepada semua orang, khususnya dalam pramuka ini nilai kebaikan yang diharapkan dapat diraih melalui upaya penanaman yaitu untuk membentuk generasi yang mandiri, tangguh dan bermoral.

c. Nilai Keindahan

Panduan tingkat pencapaian nilai keindahan dalam kegiatan kepramukaan di SMP PGRI Jogoroto menyangkut beberapa aspek, baik indah dari segi seni, kesehatan, kebersamaan, kerapian, maupun kerjasama. Contoh pioneering, setiap anggota pramuka dibutuhkan sikap ketelitian dan seni keindahan untuk merangkai menjadi bentuk apapun.

d. Nilai Kemanfaatan

Tolak ukur kemanfaatan bagi anggota pramuka itu disesuaikan dengan bakat dan minatnya anak sehingga dengan mudah untuk menanamkan nilai-nilai agama Islam. Rata-rata nilai kemanfaatan dalam kegiatan pramuka di SMP PGRI Jogoroto membidik anak menjadi disiplin dan mandiri, sigap dalam instruksi, dan tanggung jawab dalam tindakan.

Sebagaimana dikatakan oleh Anas Salahudin, nilai adalah suatu yang diyakini dan dipercayai sebagai norma atau kepatuhan yang dianut seseorang atau kelompok masyarakat. Nilai menyangkut empat aspek yaitu:
a. Nilai kebenaran;
b. Nilai kebaikan;
c. Nilai keindahan;
d. Nilai kemanfaatan. ${ }^{12}$

\section{Tujuan Penanaman Nilai-nilai Agama Islam}

Tujuan dari penanaman nilai di pramuka adalah pertama, memberikan pengetahuan kepada peserta didik sesuai dengan syarat kepanduan pramuka. Kedua, mengetahui cara atau konsep dari penggunaan kolone tongkat. Ketiga, membentuk sikap peserta didik yang

12 Anas Salahudin, Irwanto Alkrienciehie, Pendidikan Karakter:Pendidikan Berbasis Agama dan Budaya Bangsa, (Bandung: Pustaka Setia, 2013), 233. 
disesuaikan dengan darma pramuka. Dengan demikian potensi yang dimiliki peserta didik dapat berkembang dan terbina dengan sempurna. Berdasarkan observasi ketika materi kolonel tongkat, dimana seorang pembina memberikan pengetahuan kepada anggota pramuka bagaimana menggunakan tongkat saat posisi hormat, istirahat, berjalan ke samping kanan dan kekiri. Kemudian seorang pembina menginstruksikan salah satu dari mereka untuk memimpin didepan menyiapkan dan mempraktekkan untuk bermodel layaknya pembina. Bedasarkan pengamatan peneliti melalui pembinaan bisa terbentuk sikap taat dan percaya diri.

Adapun secara teori konteks tujuan pembelajaran menurut Sudirman yang secara eksplisit diusahakan untuk dicapai dengan tindakan instruksional yang berbentuk pengetahuan dan keterampilan. Apabila ditinjau secara umum, tujuan belajar dapat dihubungkan dengan tujuan pembelajaran pendidikan karakter, yaitu sebagai berikut: Untuk mendapatkan pengetahuan, lebih besar perkembangannya dalam kegiatan belajar, Penanaman konsep dan keterampilan, Pembentukan sikap..$^{13}$

Hasil analisis menunjukkan bahwa tujuan yang ingin dicapai dalam penanaman nilai-nilai agama Islam melalui kegiatan ekstrakurikuler pramuka di SMP PGRI Jogoroto sudah sesuai dengan teori Sudirman.

\section{Metode Penanaman Nilai-nilai Agama Islam}

Metode yang diterapkan dalam kegiatan ekstrakurikuler pramuka berkenaan dengan penanaman nilai-nilai agama Islam di SMP PGRI Jogoroto antara lain metode menasehati (pembina memberikan sejumlah instruksi berkenaan dengan pelatihan kolone tongkat), metode serbamembiarkan (metode yang sesuai dengan materi kolone tongkat adalah metode serba-membiarkan karena anak didik diperlukan latihan terus menerus untuk meraih ketangkasan para anggota pramuka, dan kesabaran seorang pembina dalam melatih. Kalau dipramuka lebih memperbanyak instruksi positif saja, maka anak itu akan rajin, terampil, dan akan tumbuh sikap tanggung jawabnya), metode model (berdasarkan hasil observasi bahwa metode yang bisa diterapkan dalam kegiatan pramuka tidak lepas dari metode model karena apa-apa yang di praktekkan oleh seorang pembina maka akan digerakkan oleh anggota pramuka, semisal pada materi kolone tongkat).

13 Salahudin, Anas dan Irwanto Alkrinciehie, Pendidikan Karakter: Pendidikan Berbasis Agama dan Budaya Bangsa, (Bandung: Pustaka Setia, 2013), 61. 
Berdasarkan teori Achmadi yang termuat dalam buku Pendidikan Nilai; Kajian teori dan Praktek di Sekolah, beliau mengungkapkan bahwa metode yang ditempuh untuk mencapai tujuan pendidikan nilai, sebagai berikut:

a. Metode menasihati (moralizing),

Yaitu metode pendidikan nilai dimana seorang pendidik secara langsung mengajarkan sejumlah nilai yang harus menjadi pegangan hidup peserta didik. Dalam metode ini pendidik dapat menggunakan khotbah, berpidato, memberikan nasihat, atau memberikan instruksi kepada peserta didik agar menerima saja sejumlah nilai sebagai pegangan hidup.

b. Metode serba-membiarkan (a laissezfaire attiitude),

Yaitu metode pendidikan nilai yang seorang pendidik memberikan kesempatan seluas-luasnya kepada peserta didik untuk menentukan pilihan terhadap nilai-nilai yang ditawarkan oleh pendidik. Pendidik hanya memberikan penjelasan tentang nilai-nilai tanpa memaksakan kehendaknya sendiri mengenai nilai yang seharusnya dipilih oleh peserta didik, tetapi setelah memberikan penjelasan pendidik mempersilahkan peserta didik mengambil sikap sendiri-sendiri.

c. Metode model (modeling),

Yaitu metode pendidikan nilai yang seorang pendidik mencoba meyakinkan peserta didik bahwa nilai-nilai tertentu itu memang baik dengan cara memberikan contoh dirinya atau seseorang sebagai model penghayat nilai tertentu, pendidik berharap peserta didik tergerak untuk menirunya. ${ }^{14}$

Berdasarkan hasil dari menelaah teori dan hasil pengumpulan data, ada keterkaitan diantara keduanya.

\section{Materi Penanaman Nilai-nilai Agama Islam}

Kegiatan ekstrakurikuler pramuka di SMP PGRI Jogoroto dilaksanakan setiap hari Jum'at pukul 14.00 WIB. Materi kepanduan dalam rangka penanaman nilai-nilai agama Islam yang sedang berlangsung di pramuka SMP PGRI Jogoroto adalah pioneering dan kolone tongkat. Adapun selama kegiatan nilai-nilai yang ditanamkan meliputi: nilai akidah dan nilai akhlak.

14 Zakiyah, Qiqi Yuliati dan Rusdiana, Pendidikan Nilai; Kajian teori dan Praktek di Sekolah, (Bandung: Pustaka Setia, 2014), 220. 
a. Nilai Akidah,

Bentuk penanaman nilai akidah pada anggota pramuka di SMP PGRI Jogoroto meliputi: membaca do'a sebelum kegiatan berlangsung, mengakhiri kegiatan pramuka dengan disertai do'a pula, menghafal 5 surat pendek, serta selama kegiatan berlangsung terdengar suara adzan maka kegiatan pramuka tersebut istirahat sejenak guna menjawab adzan yang sedang dikumandangkan.

b. Nilai Akhlak, meliputi:

1) Mandiri dan tanggung jawab (Hal ini berdasarkan wawancara dengan para anggota pramuka yang menyatakan tentang perasaan mengikuti ektra pramuka bahwa mereka ingin menjadi anak yang mandiri dan tanggung jawab yang tinggi. Seorang pembina juga menuturkan bahwa anak-anak itu mandiri, kalau ada acara kegiatan pramuka ada peralatan yang kurang, mereka sendiri yang meminjam ke sekolah lain. Apalagi kalau ada lomba-lomba mereka senang banget, bulan kemaren ada lomba. Alhamdulillah dapat juara I tata busana, juara III tata boga di LT III Sumberboto dan mendapat juara pioneering dengan kategori tersabar. Berarti mereka tanggung jawab dengan keputusannya mengikuti lomba)

2) Disiplin (Berdasarkan hasil pengamatan peniliti, anak-anak sudah menunjukkan sikap disiplin waktu saat latihan kegiatan ekstrakurikuler pramuka)

3) Hormat dan santun (Berdasarkan hasil observasi juga, sewaktu peneliti ikut berpartisipasi dalam kegiatan, mereka pun menyapa hangat dengan orang yang baru mereka kenal, dan sikap santunnya juga mereka tunjukkan dengan salam berjabat dengan peneliti saat kegiatan observasi berlangsung. Peniliti juga menjumpai sikap anggota pramuka yang rela memberikan tempat duduknya kepada seorang pembina yang baru hadir dalam perkumpulan Bahkan, tutur kata mereka juga masih terjaga dengan sikap hormatnya kepada seorang pembina pramuka).

4) Percaya diri dan kerja keras (Berdasarkan hasil wawancara dengan seorang pembina menuturkan sikap percaya dirinya anak-anak muncul lebih waktu ada event lomba, meskipun sekolah mereka jauh dari perkotaan tetapi mereka masih bisa tampil percaya diri melawan lomba dan hasil observasi menunjukkan bahwa sikap kerja kerasnya anak-anak mereka tunjukkan saat latihan kolone tongkat, seorang anggota pramuka bernama Aji setiwan dengan tanpa kenal lelah 
memandu teman-temannya untuk bisa baris-berbaris dengan menggunakan tongkat, dan anggota yang lain pun tidak putus asa untuk berusaha bisa. Latihan kolone tongkat peneliti lihat tidak mudah kecuali dengan konsentrasi yang baik, bahkan seorang pemimpin di depan tidak selalu benar dalam menginstrusikan gerakan baris-berbarisnya, kemudian di ingatkan dengan anggota yang lain).

5) Kepemimpinan dan keadilan (Hal ini sesuai dengan hasil observasi peneliti bahwa tujuan dari pembinaan dalam kegiatan pramuka adalah anak di didik menjadi pemimpin baik kepada dirinya dan lingkungannya, seperti dicontohkan saat latihan kolone tongkat. Berlatih kolone tongkat tidak bisa tanpa panduan dari seorang pemimpin. Untuk aturan main dari latihan baris berbaris juga tidak bisa memihak kepada siapapun karena teman dekat yang menjadikan berkurangnya tingkat kesalahan, akan tetapi ketika ada anggota pramuka yang salah dalam gerakan maka ia harus mengulang dan berlatih sampai bisa).

Sedangkan konsepsi Islam dalam sistem nilai menurut Jusuf Amir Faisal mencakup tiga komponen nilai (norma) yaitu, nilai akidah, nilai syari'ah dan nilai akhlak. ${ }^{15}$

a. Nilai Akidah

Spiritual merupakan suatu hal yang sangat perlu dimiliki bagi setiap manusia. ${ }^{16}$ Akidah didefinisikan sebagai sesuatu yang mengikat hati berupa keimanan pada ketuhanan (rububiyah) Allah SWT, keilahian-Nya (uluhiyah), nama-nama-Nya, dan ketunggalan-Nya yang tidak bersekutu, dengan (implementasi) ibadah, permohonan dan pengorientasian serta pembebasan diri dari segala hal yang disembah dari selain Allah SWT. ${ }^{17}$

Adapun nilai akidah atau keimanan ini Allah menjelaskan dalam surat Lukman ayat 13, berbunyi:

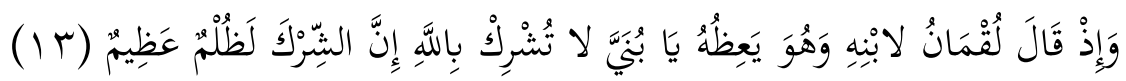

"Dan (ingatlah) ketika Luqman berkata kepada anaknya, di waktu ia memberi

${ }^{15}$ Jusuf Amir Faisal, Reorientasi Pendidikan Islam (Jakarta: Gema Insani Pres, 1995), 230.

16 Moch. Sya'roni Hasan dan Nur Arifatul Jannah, Pendidikan Agama Islam Berbasis Pesantren Dalam Peningkatan Kecerdasan Spiritual Siswa Di Smp Unggulan Al-Falah Pacul Bojonegoro (Tarbawi : Jurnal Studi Pendidikan Islami, Vol 6 No 01 (2018)

17 Khalid Sayyid Rusyah, Menggapai Nikmatnya Beribadah dalam konsep Pendidikan Islam (Jakarta: Cakrawala Publishing, 2009), 24. 
pelajaran kepadanya: "Hai anakku, janganlah kamu mempersekutukan Allah, Sesungguhnya mempersekutukan (Allah) adalah benar-benar kezaliman yang besar". 18

b. Nilai Syari'ah

Menurut Jalaludin proses pembentukan kepribadian ini dapat dilakukan dengan cara membina nilai-nilai ke Islaman dalam hubungan dengan Allah SWT. Nilai Ke Islaman dalam hubungan dengan Allah SWT dapat dilakukan dengan cara:

1) Beriman kepada Allah SWT,

2) Mengerjakan perintah dan menjauhi larangannya,

3) Bertaqwa kepadanya,

4) Mensyukuri nikmat Allah dan tidak berputus harapan terhadap rahmatnya,

5) Berdo'a kepada Tuhan selalu, mensucikan, dan membesarkan-Nya dan selalu mengingat Allah,

6) Menggantungkan segala perbuatan masa depan kepada-Nya.

c. Nilai Akhlak

Akhlak merupakan sendi ajaran islam yang tidak boleh diabaikan. Karena akhlak seseorang merupakan cerminan dari sempurna tidaknya iman orang tersebut. Semakin baik akhlaknya semakin sempurna iman orang tersebut. Rasulullah SAW bersabda: "Orang mukmin yang paling sempurna imannya adalah yang paling sempurna akhlaknya".

Ucapan-ucapan Nabi yang berkenaan dengan pembinaan akhlak yang mulia itu diikuti pula oleh perbuatannya dan kepribadiannya. Beliau dikenal sebagai orang yang Shidiq (benar), amanah (terpercaya), tabligh (menyampaikan dakwah), fatanah (cerdas). Selanjutnya beliau juga sebagai orang yang taat beribadah kepada Allah, jauh dari perbuatan maksiat, pemaaf, sabar, lapang dada, menghargai pendapat orang lain, menyayangi kaum yang lemah, seperti anak yatim, para janda yang kehilangan perlindungannya dan sebagainya. ${ }^{19}$

Sudah menjadi kewajiban manusia untuk menanamkan akhlak kepada anaknya dengan menghormati orang tua, guru maupun kepada orang yang umurnya lebih diatasnya, dengan memberi contoh dengan ungkapan-ungkapan yang baik. Sebagaimana dijelaskan dalam surat Lukman ayat 14:

\footnotetext{
18 al Quran, 31:13.

${ }^{19}$ Ibid., 77
} 


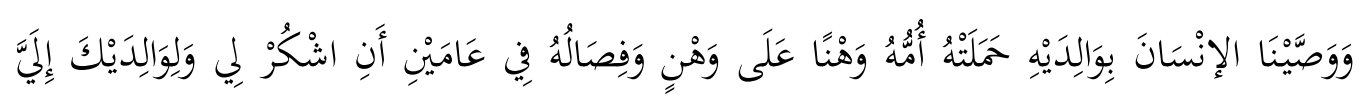

"Dan Kami perintahkan kepada manusia (berbuat baik) kepada dua orang ibubapanya; ibunya telah mengandungnya dalam Keadaan lemah yang bertambahtambah, dan menyapihnya dalam dua tahun. bersyukurlah kepadaku dan kepada dua orang ibu bapakmu, hanya kepada-Kulah kembalimu". 20

Berdasarkan hasil analisis atas teori dan hasil pengumpulan data menunjukkan sudah sesuai akan tetapi ada salah satu nilai agama Islam (nilai ibadah) yang belum terlaksana dengan baik dikarenakan adanya situasi materi kepramukaan yang sedang berlangsung di SMP PGRI Jogoroto.

\section{B. Faktor Pendukung dan Penghambat Penanaman Nilai-nilai Agama Islam melalui Kegiatan Ekstrakurikuler Pramuka di SMP PGRI Jogoroto}

Setiap kegiatan termasuk juga dalam kegiatan ekstrakurikuler pramuka untuk menanamkan nilai-nilai agama Islam kepada para anggota pamuka di SMP PGRI Jogoroto masih terdapat kendala baik adanya faktor pendukung maupun adanya faktor penghambatnya, yaitu:

\section{Faktor Pendukung}

a. Aspek psikologis berupa motivasi siswa, (hal ini berdasarkan penuturan oleh Munawaroh yang merupakan salah seorang anggota pramuka bahwa motivasi dia ikut pramuka itu agar mengenal pramuka lebih dalam, disamping itu karena ektra pramuka di wajibkan dan yang terpenting ia ingin bisa hidup mandiri dan kerjasama dengan temanteman).

b. Aspek lingkungan sosial berupa seorang pembina (guru) mampu menunjukkan sikap dan perilaku yang simpatik, ( senada dengan pernyataan oleh Putri Nanda S. yang merupakan salah seorang anggota pramuka di SMP PGRI Jogoroto menuturkan bahwa kakak pembina pramuka bersikap tegas dalam membina pramuka. Kak Ali Mashar menambahkan pula bahwa seorang pembina itu juga harus punya kemampuan membina artinya harus bisa memahami peserta didik dan mampu menguasai materi dalam internalisasi moral/akhlak).

c. Aspek pendekatan, dalam menunjang keefektifan dan efisiensi proses pembelajaran materi tertentu, (Hal ini sesuai dengan hasil observasi bahwa dalam membina siswa dalam proses kegiatan pramuka penting

${ }^{20}$ Al-Qur'an, 31:14. 
untuk seorang pembina mengetahui proses pendekatan yang diterapkan. Contoh: ketika materi kolone tongkat ada masa anak itu bosan maka pembina langsung membangun motivasi anggota pramuka dengan cara melibatkan anggota pramuka dalam proses latihan dan kepemimpinan).

Secara teori dalam bukunya Muhibbin Syah berjudul "Psikologi Belajar", mengungkapkan bahwa faktor-faktor yang mempengaruhi penanaman nilai-nilai agama Islam meliputi:

1) Faktor Psikologis berupa motivasi siswa

Motivasi dibedakan menjadi dua yaitu a) motivasi intrinsik, adalah hal dan keadaan yang berasal dari dalam diri siswa sendiri yang dapat mendorongnya melakukan belajar. Termasuk dalam motivasi intrinsik siswa adalah perasaan menyenangi materi dan kebutuhannya terhadap materi tersebut misalnya untuk kehidupan masa depan siswa yang bersangkutan. b) motivasi ekstrinsik, adalah hal dan keadaan yang berasal dari luar individu siswa sendiri yang dapat mendorongnya melakukan belajar. Pujian dan hadiah, peraturan/ tata tertib sekolah, suri teladan orang tua, guru dan seterusnya merupakan contoh-contoh konkret motivasi ekstrinsik yang dapat menolong siswa dalam belajar.

2) Faktor Lingkungan Sosial

Lingkungan sekolah seperti para guru, para staf administrasi, dan teman-teman sekelas dapat mempengaruhi semangat belajar seorang siswa. Para guru yang selalu menunjukkan sikap dan perilaku yang simpatik dan memperlihatkan suri teladan yang baik dan rajin khususnya dalam hal belajar, misalnya rajin membaca dan berdiskusi, dapat menjadi daya dorong yang positif bagi kegiatan belajar siswa.

3) Faktor Pendekatan Belajar

Pendekatan belajar, seperti yang telah diuraikan secara panjang lebar pada subbab sebelumnya, dapat dipahami sebagai segala cara atau strategi yang digunakan dalam menunjang keefektifan dan efisiensi proses pembelajaran materi tertentu. Strategi dalam hal ini berarti seperangkat langkah operasional yang di rekayasa sedemikian rupa untuk memcahkan masalah atau mencapai tujuan belajar tertentu. ${ }^{21}$

2. Faktor penghambat

Berdasarkan pernyataan kak Ria, adapun faktor yang menghambat penanaman nilai agama Islam melalui kegiatan ekstrakurikuler pramuka di SMP PGRI Jogoroto adalah pertama, kurangnya pendidikan orang tua

${ }^{21}$ Muhibbin Syah, Psikologi Belajar, (Jakarta: Rajawali Pers, 2012), 145-156. 
kepada anak ketika di sekolah di suruh selalu mengawali dan mengakhiri kegiatan dengan berdoa, kemudian di ajak sholat, di ajari sopan sama orang yang lebih tua atau gurunya, akan tapi ketika dirumah terkadang sama orang tua hal itu semua diabaikan. Kedua, lingkungan yang kurang mendukung alasannya warga sekitar kebanyakan punya anggapan negatif kepada anak-anak yang sekolah di SMP PGRI Jogoroto, mereka anggap anak-anak urakan saja yang sekolah di SMP PGRI Jogoroto padahal kalaupun ada jenis kriminalitas yang dilakukan anak-anak maka pihak sekolah tidak segan-segan melaporkan ke polisi. Ketiga, perbedaan kemampuan anak, jadi harus sabar menghadapi anak-anak yang seperti itu. Demikian itu termasuk menghambat.

Hal ini sesuai dengan teori yang dikemukakan oleh $\mathrm{H}$. Baharuddin dalam bukunya yang berjudul Pendidikan Psikologi dan Perkembangan yang mengatakan bahwa faktor penanaman nilai-nilai agama Islam adalah:

a. Kurangnya pendidikan orang tua kepada anak,

b. Lingkungan yang kurang mendukung,

c. Perbedaan IQ siswa ${ }^{22}$.

\section{Kesimpulan}

Pedoman penanaman nilai-nilai Agama Islam melalui kegiatan ekstrakurikuler pramuka di SMP PGRI Jogoroto menyangkut empat aspek yaitu nilai kebenaran, nilai kebaikan, nilai keindahan, nilai kebermanfaatan. Penanaman nilai-nilai yang diterapkan di SMP PGRI Jogoroto melalui kegiatan pramuka bertujuan untuk: Mendapatkan pengetahuan, Penananan konsep dan keterampilan, Pembentukan sikap. Metode penanaman nilai-nilai agama Islam meliputi metode menasihati, metode serba-membiarkan, dan metode model. Materi penanaman nilai-nilai agama Islam terdiri dari nilai akidah dan nilai akhlak.

Faktor pendukung dan penghambat penanaman nilai-nilai gama Islam melalui kegiatan ekstrakurikuler pramuka di SMP PGRI Jogoroto. Faktor pendukung, yaitu faktor psikologis berupa motivasi siswa, faktor lingkungan sosial, dan faktor pendekatan belajar. Faktor penghambat, diantaranya kurangnya pendidikan orang tua kepada anak, lingkungan yang kurang mendukung, dan perbedaan IQ siswa.

${ }^{22}$ H. Baharuddin, Pendidikan Psikologi Perkembangan, (Yogyakarta: Ar Ruzz Media, 2010), 213. 


\section{Daftar Pustaka}

Baharuddin, Pendidikan Psikologi Perkembangan. Yogyakarta: Ar Ruzz Media, 2010.

Hasan, Moch. 2019. "Internalisasi Nilai Toleransi Beragama”. DAR EL-ILMI : Jurnal Studi Keagamaan, Pendidikan Dan Humaniora 6 (1), 79-111. http://www.ejurnal.unisda.ac.id/index.php/dar/article/view/1469.

Zakiyah, Qiqi Yuliati dan Rusdiana, Pendidikan Nilai; Kajian Teori dan Praktek di Sekolah, (Bandung: Pustaka Setia, 2014.

Hasan, Moch. Sya'roni dan Nur Arifatul Jannah, Pendidikan Agama Islam Berbasis Pesantren Dalam Peningkatan Kecerdasan Spiritual Siswa Di Smp Unggulan AlFalah Pacul Bojonegoro (Tarbawi : Jurnal Studi Pendidikan Islami, Vol 6 No 01 (2018),

Jusuf Amir Faisal, Reorientasi Pendidikan Islam (Jakarta: Gema Insani Pres, 1995. Kwartir Nasional-Gerakan Parmuka, Kursus Pembina Pramuka Mahir Tingkat Dasar (Jakarta:t.p.2011

Majid, Abdul. Belajar dan Pembelajaran Pendidikan Agama Islam. Bandung:PT Remaja Rosda Karya, 2012.

Ramayulis, Ilmu Pendidikan islam. Jakarta: Kalam Mulia, 2002.

Roqib, Moh. Ilmu Pendidikan islam. Yogyakarta: LKIS, 2011.

Rusyah, Khalid Sayyid. Menggapai Nikmatnya Beribadah dalam konsep Pendidikan Islam. Jakarta: Cakrawala Publishing, 2009.

Salahudin, Anas dan Irwanto Alkrienciehie, Pendidikan Karakter: Pendidikan Berbasis Agama dan Budaya Bangsa. Bandung:Pustaka Setia, 2013

Suprayogo, Imam. Pengembangan Pendidikan Karakter. UIN Maliki Press, 2013. Syah,Muhibbin Psikologi Belajar. Jakarta: Rajawali Pers, 2012.

Tafsir, Ahmad. Epistimologi untuk Ilmu Pendidikan Islam. Bandung: 1995.

Zakiyah, Qiqi Yuliati dan Rusdiana, Pendidikan Nilai; Kajian teori dan Praktek di Sekolah. Bandung: Pustaka Setia, 2014. 